\title{
Produtos Alternativos para o Controlo de Doenças das Plantas
}

Mário Lúcio Vilela de Resende Fabrício Ávila Rodrigues Deila Magna dos Santos Botelho Pedro Martins Ribeiro Junior Tharyn Reichel Leonor Guerra-Guimarães*

\author{
Alternative Products to Plant Disease Control. \\ Phosphites and silicates, although considered \\ as plant mineral nutrients, can also be used as \\ alternative products for plant disease control. \\ These inorganic minerals can act directly \\ against the phytopathogenic organisms and/or \\ induce the plant defense responses.
}

\begin{abstract}
Os fosfitos e os silicatos, embora considerados nutrientes minerais das plantas, podem também funcionar como produtos alternativos no controlo de doenças em diferentes culturas. Estes minerais inorgânicos podem atuar diretamente contra os microrganismos patogénicos e/ou induzir as respostas de defesa das plantas.
\end{abstract}

\section{Introdução}

Os pesticidas (ex., inseticidas, fungicidas e herbicidas) são produtos utilizados pelos agricultores para proteger as culturas contra microrganismos patogénicos, pragas e doenças. Se os pesticidas forem mal utilizados podem afetar a qualidade da água e do solo, a biodiversidade e os ecossistemas, e serem detetados nos alimentos. A utilização criteriosa dos pesticidas e a promoção da proteção integrada das culturas é o caminho para uma agricultura mais sustentável. Uma alternativa aos pesticidas são os minerais inorgânicos, como os fosfitos e os silicatos, de custos reduzidos e considerados seguros para os seres humanos e para o ambiente por possuírem baixa toxicidade $[1,2]$. Estes compostos são também nutrientes minerais que, per se, promovem o crescimento e a produção vegetal, reduzindo o uso de fertilizantes. A utilização destes minerais inorgânicos na aǵricultura poderá ter um papel importante na transição para o sistema de produção alimentar agroecológico e para a economia limpa que se pretende cada vez mais circular.

Os fosfitos são compostos que resultam da neutralização do ácido fosforoso $\left(\mathrm{H}_{3} \mathrm{PO}_{3}\right)$ por uma base, como o hidróxido de sódio, hidróxido de amónio ou hidróxido de potássio, este último o mais utilizado (Figura 1). Outros sais de fosfito, como os de manganês, zinco e cobre, também são comercializados [3].

Embora as plantas não tenham capacidade de absorver diretamente os fosfitos, estes ao serem oxidados a fosfatos pelas bactérias do solo, são absorvidos pelo sistema radicular das plantas como nutrientes [4]. Os
$\mathbf{A}$<smiles>O=[PH]([O-])[O-]</smiles>

Ião fosfito

Ião fosfato

B

$$
\mathrm{H}_{3} \mathrm{PO}_{3} \stackrel{\mathrm{KOH}}{\longrightarrow} \mathrm{KH}_{2} \mathrm{PO}_{3} \stackrel{\mathrm{KOH}}{\longrightarrow} \mathrm{K}_{2} \mathrm{HPO}_{3}
$$

Figura 1 - Conversão entre os iões fosfito e fosfato (A) e formação do fosfito de potássio pela reação do ácido fosforoso com hidróxido de potássio (B) [3].

fosfitos podem ainda ter uma ação tóxica direta sobre os microrganismos patogénicos $[1,3,5]$ e/ou induzir as respostas de defesa da planta $[1,6,7]$. Estes minerais são transportados pelos tecidos condutores, tanto pelo floema como pelo xilema. Devido a esta característica, podem ser aplicados por pulverização foliar e ser transportados para as raízes para o controlo de microrganismos patogénicos do solo; ou, se aplicados nas raízes, controlarem os agentes patogénicos da parte aérea [1,5]. Diversos trabalhos de investiǵação têm mostrado a eficácia dos fosfitos no controlo de importantes doenças provocadas por fungos (ex., a antracnose e o mofo branco da soja ou a cercosporiose em cafeeiro) e por bactérias (ex., "o fogo bacteriano" na macieira) [8-11] (Tabela 1). 
Tabela 1 - Aplicação de fosfitos e silicatos no controlo de doenças em culturas agrícolas.

\begin{tabular}{|c|c|c|c|c|c|}
\hline \multicolumn{2}{|c|}{ Agente patogénico } & \multirow{2}{*}{$\begin{array}{l}\text { Planta hospedeira } \\
\text { Macieira }\end{array}$} & \multirow{2}{*}{$\begin{array}{l}\text { Doença } \\
\text { Fogo bacteriano }\end{array}$} & \multirow{2}{*}{$\begin{array}{l}\text { Fosfito/silicato } \\
\text { Fosfito de potássio }\end{array}$} & \multirow{2}{*}{$\begin{array}{l}\text { Ref. } \\
{[8]}\end{array}$} \\
\hline.$\tilde{\underline{n}}$ & Erwinia amylovora & & & & \\
\hline$\breve{d}$ & Xanthomonas axonopodis & Feijoeiro & Queima bacteriano & Fosfito de zinco & {$[12]$} \\
\hline \multirow{20}{*}{$\begin{array}{c}\text { ñ } \\
\text { o } \\
5 \\
5\end{array}$} & Blumeria graminis & Aveia & Oídio & Silicatos & {$[2]$} \\
\hline & Cercospora coffeicola & Cafeeiro & Cercosporiose & Fosfito de potássio & [11] \\
\hline & Colletotrichum gloeosporioides & Macieira & Antracnose & Fosfito de potássio & {$[13]$} \\
\hline & Colletotrichum truncatum & Soja & Antracnose & Fosfito de potássio & [9] \\
\hline & Cylindrocladium spathiphylli & Bananeira & Necrose das raízes & Ácido monossilícico & {$[14]$} \\
\hline & Erysiphe necator & Videira & Oídio & Silicato de potássio & [15] \\
\hline & Fusarium oxysporum & Bananeira & Doença do Panamá & Silicato de cálcio & [16] \\
\hline & Fusarium solani & Batateira & Fusariose & Silicato de cálcio & [16] \\
\hline & Bipolaris oryzae & Arroz & $\begin{array}{l}\text { Helmintosporiose (Mancha } \\
\text { parda) }\end{array}$ & Silicato de cálcio & [17] \\
\hline & Hemileia vastatrix & Cafeeiro & Ferrugem & Fosfito de potássio & [11] \\
\hline & $\begin{array}{l}\text { Pyricularia oryzae (sin. } \\
\text { Magnaporthe oryzae) }\end{array}$ & Arroz & Piriculariose & Silicato de cálcio & [18] \\
\hline & Mycosphaerella fijiensis & Bananeira & Sigatoka da bananeira & Silicato de sódio & {$[19]$} \\
\hline & Phakopsora euvitis. & Videira & Ferrugem & Fosfito de potássio & [20] \\
\hline & Podosphaera pannosa & Roseira & Oídio & Silicato de cálcio & {$[21]$} \\
\hline & Podosphaera xanthii & Pepineiro & Oídio & Silicato de potássio & {$[2]$} \\
\hline & Phoma costaricensis & Cafeeiro & Mancha de phoma & Fosfito de potássio & [3] \\
\hline & Sclerotinia sclerotiorum & Soja & Mofo branco & Fosfitos & {$[10]$} \\
\hline & Uromyces vignae & Feijoeiro & Ferrugem & Silicato de sódio & {$[2]$} \\
\hline & Venturia inaequalis & Macieira & Pedrado da macieira & Fosfito de potássio & {$[22]$} \\
\hline & Verticillium dahliae & Cacaueiro & Murcha & Fosfito de potássio & [23] \\
\hline \multirow{3}{*}{ 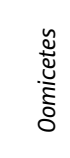 } & Phytophthora infestans & Batateira & Míldio & Fosfito de potássio & {$[24]$} \\
\hline & Phytophthora cinnamomi & Eucalipto & Míldio & Fosfitos & {$[5,25]$} \\
\hline & Pseudomonas syringae & Castanheiro da Índia & Cancro bacteriano & Fosfitos & [26] \\
\hline
\end{tabular}

O silício (Si) é o segundo elemento químico mais abundante na crosta terrestre, a seguir ao oxigénio [2]. Ocorre normalmente na natureza associado ao oxigénio sob a forma de dióxido de silício $\left(\mathrm{SiO}_{2}\right)$. Embora não seja essencial para as plantas, o Si é considerado um nutriente benéfico, pois promove o desenvolvimento e aumenta a produção de muitas espécies, tanto de monocotiledóneas (ex., arroz) como de dicotiledóneas (ex., pepineiro e batateira) $[2,27]$. As plantas cultivadas em ambientes ricos em Si apresentam uma composição química particular que lhes confere maior resistência ao stress abiótico e biótico [2]. Diferentes fontes de Si, sólido (cimento, metassilicato de cálcio e silicato de cálcio) ou líquido (ácido monossilícico, silicato de potássio e silicato de sódio), têm sido utilizadas em culturas agrícolas tanto no campo como em estufa [27]. Para que estas fontes sejam eficientes no fornecimento de Si às plantas, deverão: (i) ter uma alta concentração de Si solúvel; (ii) ser de fácil armazenamento e aplicação e; (iii) não conter metais pesados [27]. Das diversas fontes de silício utilizadas na agricultura, destacam-se os silicatos, que são provenientes de escórias da siderurgia do ferro ou do aço. Durante a fundição, quando o ferro é exposto a temperaturas elevadas, as impurezas são separadas do metal fundido e podem ser removidas sob a forma de silicatos de cálcio e magnésio. A escória possui várias aplicações 
comerciais, nomeadamente na engenharia civil e na agricultura (ex., correção da acidez do solo ou como aditivos de fertilizantes). A utilização deste subproduto da indústria na agricultura resulta em benefício ambiental, económico e social, contribuindo para a economia limpa circular $[28,29]$.

A utilização de nanopartículas $(1-100 \mathrm{~nm})$ de $\mathrm{SiO}_{2}\left(\mathrm{SiO}_{2}-\mathrm{NPS}\right.$ ) e de sílica mesoporosa (MSNs) na agricultura é a forma mais eficiente e controlada de fornecer Si às plantas [30]. Nas culturas de trigo e de tremoceiro, as MSNs são absorvidas pelas raízes e transportadas para os caules e folhas. Após a absorção das MSNs, foi observado o aumento de atividade fotossintética e de biomassa, o que levou a um maior crescimento das plantas [30]. O fornecimento de Si às diferentes culturas agrícolas mostrou uma redução da severidade de várias doenças (ex., oídio, ferrugem) causadas por diferentes agentes patogénicos (ex., bactérias, oomicetes e fungos) [2] (Tabela 1).

\section{Os fosfitos no controlo das doenças das plantas}

Os fosfitos podem atuar diretamente sobre os fungos diminuindo a intensidade da doença, por exemplo, alterando a morfologia das hifas, ou através de modificações celulares que afetam o crescimento do micélio e da esporulação [31]. A adição de fosfito de cálcio ou fosfito de potássio inibiu a germinação de conídios e o crescimento do micélio de Fusarium solani e Phytophthora infestans $[5,24]$ em batateira. Estes resultados são importantes sob o ponto de vista epidemiológico, uma vez que a inibição da esporulação vai diminuir o potencial de inóculo no campo.

A aplicação foliar de fosfitos reduziu o tamanho da lesão causada pela bactéria Pseudomonas syringae no castanheiro da Índia [26] e a severidade do pedrado da macieira (Venturia inaequalis) em 62\% quando comparado com plantas não tratadas [22]. A pulverização de folhas de videira com fosfito de potássio dois dias após a inoculação com a ferrugem (Phakopsora euvitis) reduziu o desenvolvimento dos sintomas da doença em 58\% [20]. A aplicação de fosfitos na cultura do cafeeiro mostrou uma redução na incidência de várias doenças, nomeadamente, ferrugem, cercosporiose e mancha de Phoma $[3,11]$.

Para além do efeito direto sobre os agentes patogénicos, a aplicação de fosfitos parece também induzir algumas respostas de defesa das plantas, nomeadamente, proteínas de defesa como as proteínas PR (proteínas relacionadas com a patogenicidade), fitoalexinas, inibidores de hidrolases dos agentes patogénicos, produção de pectinas e lenhificação dos tecidos foliares [1]. Plantas de cacau (Theobroma cacao) tratadas com fosfito de potássio e inoculadas com Verticillium dahliae apresentaram um aumento na atividade das peroxidases [23]. As peroxidases são consideradas proteínas PR com diversas funções celulares, tais como a lenhificação e suberização da parede celular das plantas no local de infeção, atuando como um mecanismo de defesa [32] (Tabela 1).

Plantas de feijoeiro pulverizadas com fosfito de zinco e inoculadas com a bactéria Xanthomonas axonopodis apresentaram um aumento de atividade das enzimas fenilalanina amoníaco-liase, polifenoloxidase, $\beta$-1,3-glucanase, ascorbato-peroxidase e superóxido dismutase, e uma menor severidade da doença [12]. 0 tratamento com fosfito aumentou a capacidade antioxidante e induziu respostas de defesa com preservação da eficiência fotossintética das plantas.

\section{O silício no controlo das doenças das plantas}

Os primeiros estudos sobre o efeito do silício no controlo de doenças de plantas foram realizados por Isenosuke Onodera em arroz infetado com Pyricularia oryzae [18]. Após a aplicação foliar de Si em plantas de arroz, foi observado o aparecimento de uma camada externa eletrodensa nas microfibrilas de celulose e uma camada interna translúcida na parede das células [33]. Os depósitos de silício formados abaixo da cutícula e na parede celular das células da epiderme aumentaram a espessura e rigidez da folha, o que tem sido considerado como a explicação mais provável para o efeito do Si na proteção de diversas culturas (mono e dicotiledóneas) contra doenças e pragas e até de alguns tipos de stress abiótico (ex., seca e salinidade) [2]. As gramíneas em geral, e particularmente o arroz, são plantas acumuladoras de Si. Além disso, a deposição de Si nas células epidérmicas atrasa a penetração, a colonização (aumento do período de incubação e período de latência e redução do tamanho das lesões) e a esporulação de diversos agentes patogénicos [2].

A severidade da helmintosporiose (Bipolaris oryzae) em plantas de arroz foi reduzida com a aplicação de silicato de cálcio no solo [17]. A capacidade de absorção ativa de Si foi estudada por hidroponia em duas variedades de arroz, Oochikara e no mutante Isi1 (que não consegue absorver de forma ativa Si). Os resultados mostraram uma redução na concentração foliar de Si nos tecidos das plantas do mutante IsiT, em comparação com a variedade Oochikara, sendo mais suscetíveis à doença [34]. O uso de Si na cultura de roseira reduziu a severidade do oídio causado por Podosphaera pannosa [21].

A deposição de Si nas paredes celulares da epiderme de folhas de aveia reduziu a penetração do fungo Blumeria graminis [2]. Resultados semelhantes foram observados em folhas de feijoeiro, onde a deposição de Si juntamente com a acumulação de compostos fenólicos e g'licoproteínas ricas em hidroxiprolina reduziu o número de haustórios (estruturas 
intracelulares) formados por Uromyces vignae [2]. A interrupção no fornecimento de Si resultou num aumento das severidades do oídio e da ferrugem. Estes resultados sugerem que é necessária uma concentração mínima de Si nas folhas novas para promover o controlo das doenças [2]. Além disso, o fornecimento de Si insolúvel é menos efetivo do que o Si solúvel durante a penetração fúngica e, consequentemente, na redução da intensidade da doença. Plantas de banana-maçã (variedade suscetível) crescidas em solo contendo Si (0,39 g' de Si/kg de solo) apresentaram uma redução dos sintomas da doença do Panamá (Fusarium oxysporum), em tudo semelhante à variedade resistente [16]. Na bananeira, a aplicação de silicato mostrou uma redução na intensidade da doença de sigatoka (Mycosphaerella fijiensis) [19] e da necrose das raízes (Cylindrocladium spathiphylli) quando comparada com plantas não tratadas com Si [14]. O controlo do oídio da videira (Erysiphe necator) com silicato de potássio, por aplicação foliar, foi eficaz na redução do número de colónias do fungo [15] (Tabela 1).

Para além da formação de uma barreira física, o Si parece também induzir alguns mecanismos de defesa das plantas. A análise bioquímica de extratos foliares de plantas de pepino, após aplicação de Si e infeção por Podosphaera xanthii, revelou altas concentrações de flavonoides e compostos fenólicos associados à redução da severidade da doença [2] 0 aumento na atividade de várias enzimas relacionadas com as respostas de defesa das plantas (ex., $\beta-1,3-$ glucanase, quitinase, fenilalanina amoníaco-liase, peroxidase e polifenoloxidase) tem sido descrito em culturas como a bananeira, o pepino, o cafeeiro, o algodão, o melão, a ervilha, o arroz, a soja e o tomate, após a aplicação de Si [2].

\section{Considerações finais}

Embora o nível de eficácia destes produtos dependa do tipo de fosfito/silicato usado, método de aplicação, microrganismo patogénico e planta hospedeira, a sua utilização poderá ser um componente essencial no controlo integrado das doenças. Além disso, estes minerais inorgânicos são nutrientes importantes para a manutenção da produção, qualidade e valor dos produtos agrícolas. A divulgação destes e doutros produtos alternativos aos pesticidas no controlo de doenças das plantas, que simultaneamente aumentem a produção e qualidade das culturas, enquadra-se no "Pacto Ecológico Europeu" (Green Deal) (ec.europa.eu/info/strategy/priorities-2019-2024/ european-green-deal_pt). A política agrícola comum coloca as boas práticas ambientais no centro da agricultura e da silvicultura na UE, tendo previsto um plano de ação para impulsionar a utilização eficiente dos recursos através da transição para uma economia limpa e circular, restaurar a biodiversidade, reduzir a poluição e proteger o planeta.

\section{Agradecimentos}

Fundação para a Ciência e a Tecnologia (FCT) - LEAF/ UID/AGR/04129/2019, Conselho Nacional de Desenvolvimento Científico e Tecnológico (CNPq), Coordenação de Aperfeiçoamento de Pessoal de Nível Superior (CAPES), Fundação de Amparo à Pesquisa do Estado de Minas Gerais (FAPEMIG) e Instituto Nacional de Ciência e Tecnologia do Café (INCT-Café).

\section{Referências}

[1] M. G. Yáñez-Juárez, C. A. López-Orona, F. Ayala-Tafoya, L. Partida-Ruvalcaba, T. J. Velázquez-Alcaraz, R. Medina-López, Rev. Mex. Fitopatol. 2017, 36, 7994. DOl: 10.18781/r.mex.fit.1710-7.

[2] D. Debona, F. A. Rodrigues, L. E. Datnoff, Annu. Rev. Phytopathol. 2017, 55 , 85-107. DOI: 10.1146/annurev-phyto-080516-035312.

[3] R. J. D. Dalio, P. M. R. Junior, M. L. V. Resende, A. C. Silva, S. Blumer, V. F. Pereira, W. Osswald, S. F. Pascholati, O triplo modo de ação dos fosfitos em plantas, in W. C. Luz. (ed.). "Revisão Anual de Patologia de Plantas", Passo Fundo, RGS, Brasil, 2012, 206-242.

[4] A. E. McDonald, B. R. Grant, W. C. Plaxton, J. Plant Nutr. 2001, 24, 1505-1519. DOI: $10.1081 / P L N-100106017$.

[5] C. J. Wilkinson, J. M. Holmes, B. Dell, K. M. Tynan, J. A. McComb, B. L. Shearer, I. J. Colquhoun, G. E. St. J. Hardy, Plant Pathol. 2001, 50, 587-593. DOl: 10.1046/j.1365-3059.2001.00605.x.

[6] R. J. D. Dalio, F. Fleischmann, M. Humez, W. Osswald. PLoS One 2014, 9, 1. DOI: 10.1371/journal.pone.0087860.
[7] L. Eshraghi, J. Anderson, N. Aryamanesh, B. Shearer, J. A. McComb, G. E. S. J. Hardy, P. A. O'Brien, Plant Pathol. 2011, 60, 1086-1095. DOl: 10.1111/j.13653059.2011.02471.x

[8] S. G. Aćimović, Q. Zeng, G. C. McGhee, G. W. Sundin, J. C. Wise. Front. Plant Sci. 2015, 6, 1-6. DOI: 10.3389/fpls.2015.00016

[9] M. B. S. Junior, M. L. V. Resende, E. A. Pozza, A. R. Resende, V. A. M. Vasconcelos, A. C. A. Monteiro, G. C. D. Silveira, D. M. S. Botelho, J. Plant Pathol. 2021, 103, 611-617. DOI: 10.1007/s42161-021-00747-y.

[10] M. I. C. Novaes, D. Debona, I. R. F. F.-Nacarath, V. V. Brás, F. A. Rodrigues, Acta Physiol. Plant. 2019, 41, 186. DOl: 10.1007/s11738-019-2976-9.

[11] J. A. G. Silva, M. L. V Resende, A. C. A. Monteiro, M. A. Pádua, L. G.Guimarães, F. L. Medeiros, S. A. Martins, D. M. S. Botelho. J. Phytopathol. 2019, 167, 430-439. DOI: 10.1111/jph.12814.

[12] L. C. Costa, D. Debona, P. R. Silveira, I. S. Cacique, C. E. A.-Pérez, R. S. Resende, J. R. Oliveira, F. A. Rodrigues, J. Phytopathol. 2020, 168, 641-651. DOI: 10.1111/jph.12944 
[13] L. Araújo, R. M. V.-Sanhueza, M. J. Stadnik, Trop. Plant Pathol. 2010, 35 054-059. DOI: 10.1590/S1982-56762010000100010.

[14] M. L. Vermeire, L. Kablan, M. Dorel, B. Delvaux, J. M. Risède, A. Legrève, Eur. J. Plant Pathol. 2011, 137, 621-630. DOl: 10.1007/s10658-011-9835-x.

[15] P. Bowen, J. Menzies, D. Ehret, L. Samuels, A. D. M. Glass, J. Am. Soc. Hortic. Sci. 1992, 117, 906-912. DOI: 10.21273/JASHS. 117.6.906.

[16] A. A. Fortunato, F. A. Rodrigues, K. J. T. Nascimento, Phytopathology 2012 102, 957-966. DOI: 10.1094/PHYTO-02-12-0037-R.

[17] L. E. Datnoff, G. H. Snyder, C. W. Deren, Plant Dis. 1992, 76, 1011-1013. DOI: 10.1094/PD-76-1011.

[18] I. Onodera, J. Sci. Food Agric. 1917, 180, 606-617.

[19] L. Kablan, A. Lagauche, B. Delvaux, A. Legrève, Plant Dis. 2012, 96, 273-278. DOI: 10.1094/PDIS-04-11-0274

[20] C. R. S. Buffara, F. Angelotti, D. J. Tessmann, C. D. de Souza, J. B. Vida, Semin. Cienc Agrar. 2013, 34, 3333-3340. DOl: 10.5433/1679-0359.2013v34n6Supl1p3333.

[21] R. Shetty, B. Jensen, N. P. Shetty, M. Hansen, C. W. Hansen, K. R. Starkey, H. J. L. Jørgensen, Plant Pathology. 2012, 61, 120-131. DOI: 10.1111/j.13653059.2011.02493.x

[22] R. B. Felipini, J. I. Boneti, Y. Katsurayama, Eur. J. Plant Pathol. 2016, 145 , 929-939. DOI: 10.1007/s10658-016-0881-2.

[23] P. M. R. Júnior, M. L. V. de Resende, R. B. Pereira, F. R. Cavalcanti, D. R. Amaral, M. A. de Pádua, Cienc. Agrotec. 2006, 30, 629-636. DOI: 10.1590/S141370542006000400006

[24] M. C. Lobato, F. P. Olivieri, G. R. Daleo, A. B. Andreu, J. Plant Dis. Prot. 2010 117, 102-109. DOI: 10.1007/BF03356343.
[25] P. M. Scott, P. A. Barber, G. E. S. Hardy, Australas. Plant Pathol. 2015, 44 , 431-436. DOI: 10.1007/s13313-015-0365-4.

[26] G. C. Percival, J. M. Banks, Arboric. J.: Inter. J. Urban For. 2015, 37, 7-20. DOl: 10.1080/03071375.2015.1017388.

[27] G. Gascho, Silicon sources for agriculture, in L. E. Datnoff, G. H. Snyder, G. H. Korndörfer (ed), "Studies in Plant Science", Elsevier Science, Amesterdão, Países Baixos, 2001, 197-207.

[28] A. C. F. Deus, L. T. Büll, Ciência Rural 2013, 43, 1783-1789. DOI: 10.1590/ S0103-84782013005000120.

[29] M. F. Sobral, C. W. A. do Nascimento, K. P. V. da Cunha, H. A. Ferreira, A. J. Silva, F. B. V. Silva, Rev. Bras. de Eng. Agricola e Ambient. 2011, 15, 867-872. DOI:10.1590/S1415-43662011000800015.

[30] D. Sun, H. I. Hussain, Z. Yi, J. E. Rookes, L. Kong, D. M. Cahill, Chemosphere 2016, 15, 81-91. DOI: 10.1016/j.chemosphere.2016.02.096.

[31] M. King, W. Reeve, M. B. Van der Hoek, N. Williams, J. McComb, P. A. O'Brien, G. E. St. J. Hardy, Mol. Genet. Genom. 2010, 284, 425-435. DOl: 10.1007/ s00438-010-0579-7.

[32] L. C. van Loon, E. A. van Strien, Physiol. Mol. Plant Pathol. 1999, 55, 85-97. DOI: 10.1006/pmpp.1999.0213.

[33] S. G. Kim, K. W. Kim, E. W. Park, D. Choi, Phytopathology 2002, 92, 10951103. DOI: 10.1094/PHYTO.2002.92.10.1095.

[34] L. J. Dallagnol, F. A. Rodrigues, M. V. B. Mielli, J. F. Ma, L. E. Datnoff, Phytopathology 2009, 99, 116-121. DOI: 10.1094/PHYTO-99-1-0116.
Deila Magna dos Santos Botelho

Universidade Federal de Lavras, Departamento de Fitopatologia, Lavras, MG Brasil. Doutoramento em Agronomia/Fitopatologia pela Universidade Federal de Lavras (Minas Gerais, Brasil). Pós-doutoranda do Departamento de Fitopatologia, Universidade Federal de Lavras a desenvolver investigação no Laboratório de Fisiologia do Parasitismo na área de Fitopatologia com enfoque em indução de resistência em plantas. deilamagna@hotmail.com ORCID.org/0000-0002-3047-0164

\section{Fabrício de Ávila Rodrigues}

Universidade Federal de Viçosa, Departamento de Fitopatologia, Viçosa, MG, Brasil.

Licenciatura em Agronomia pela Universidade Federal de Uberlândia, Mestrado em Fitopatologia pela Universidade Federal de Viçosa (UFV) e Doutoramento em Fitopatologia pela University of Florida (USA). É Professor no Departamento de Fitopatologia, orienta nos Programas de Pós-Graduação em Fitopatologia e Fisiologia Vegetal da UFV. fabricio@ufv.br ORCID.org/0000-0002-3091-0000

\section{*Leonor de Castro \\ Esteves Guerra Guimarães}

Linking Landscape, Environment, Agriculture and Food (LEAF), Instituto Superior de Agronomia, Universidade de Lisboa, Lisboa, Portugal.

Doutoramento em Biologia (especialidade de Fisiologia e Bioquímica) pela Faculdade de Ciências da Universidade de Lisboa. Investigadora Auxiliar do Instituto Superior de Agronomia da Universidade de Lisboa a desenvolver atividade no Centro de Investigação das Ferrugens do Cafeeiro (CIFC) e no Centro de Investigação em Agronomia, Alimentos, Ambiente e Paisagem (LEAF). leonorguimaraes@edu.ulisboa.pt ORCID.org/0000-0002-9676-1036

\section{Mário Lúcio Vilela de Resende}

Universidade Federal de Lavras, Departamento de Fitopatologia, Lavras, MG Brasil. Doutoramento em Applied Biology and Biochemistry, University of Bath, Inglaterra. Professor titular da Universidade Federal de Lavras, Departamento de Fitopatologia (Minas Gerais, Brasil). Leciona as disciplinas de Fisiologia do Parasitismo, Bases Moleculares da Resistência de Plantas a Doenças, Patologia Florestal e Manejo Integrado de Doenças de Plantas.

mlucio@ufla.br

ORCID.org/0000-0002-5702-0016

\section{$>$}

\section{Pedro Martins Ribeiro Júnior}

Empresa Brasileira de Pesquisa Agropecuária, Petrolina, PE, Brasil.

Doutoramento em Agronomia/Fitopa- tologia pela Universidade Federal de Lavras (Minas Gerais, Brasil). Investigador da empresa EMBRAPA Semiárido (Pernambuco, Brasil) a desenvolver atividade na área de fitopatologia, interação planta-patógeno e mecanismos de defesa das plantas. pedro.ribeiro@embrapa.br ORCID.org/0000-0003-4894-437X

\section{Tharyn Reichel}

Universidade Federal de Lavras, Departamento de Fitopatologia, Lavras, MG Brasil.

Doutoramento em Biotecnologia Vegetal pela Universidade Federal de Lavras (Minas Gerais, Brasil). Pós-doutoranda do Departamento de Fitopatologia da Universidade Federal de Lavras a desenvolver investigação no Laboratório de Fisiologia do Parasitismo na área de Biotecnologia Vegetal. tharynr@gmail.com ORCID.org/0000-0003-2754-0245 